\title{
Action for Rehabilitation from Neurological Injury (ARNI): A pragmatic study of functional training for stroke survivors
}

\author{
Cherry Kilbride $^{1}$, Meriel Norris ${ }^{1}$, Nicola Theis $^{2}$, Amir A. Mohagheghi $^{2 *}$ \\ ${ }^{1}$ Centre for Research in Rehabilitation, School of Health Sciences and Social Care, Brunel University, London, UK \\ ${ }^{2}$ Centre for Sports Medicine and Human Performance, School of Sport and Education, Brunel University, London, UK; \\ *Corresponding Author: amir.mohagheghi@brunel.ac.uk
}

Received 5 June 2013; revised 8 July 2013; accepted 20 July 2013

Copyright (C) 2013 Cherry Kilbride et al. This is an open access article distributed under the Creative Commons Attribution License, which permits unrestricted use, distribution, and reproduction in any medium, provided the original work is properly cited.

\section{ABSTRACT}

This study evaluated the effectiveness of a twelve-week community-based functional training on measures of impairment, activity and participation in a group of stroke survivors. Isometric strength of the knee musculature, Centre-OfPressure (COP) based measures of balance, Berg Balance Scale (BBS), $10 \mathrm{~m}$ walk test, and the Subjective Index of Physical and Social Out come (SIPSO), were recorded at baseline, postintervention, and after twelve weeks (follow-up). Exercise instructors delivered training once a week in a group format at a community centre. Significant improvement was noted in the BBS $(p<0.002)$, and $10 \mathrm{~m}$ walk speed $(p=0.03)$ post intervention which remained unchanged at follow-up. Total SIPSO score improved significantly post-intervention $(p=0.044)$. No other significant differences and no adverse effects were observed. It is possible that functional training provided more opportunity for the improvement of dynamic aspects of balance control that could be captured by the BBS but not with the traditional measures of balance using COP data. Results also suggest positive effects on the level of participation, and lack of association between measures of impairment and activity. Community based functional training could be effective and used to extend access to rehabilitation services beyond the acute and sub-acute stages after stroke.

Keywords: Balance; Centre-of-Pressure;

Functional Training; Hemiplegia; ICF;

Rehabilitation; Strength; Stroke

\section{INTRODUCTION}

Stroke is the single biggest cause of severe adult disability in the UK [1], and affects between 178 and 317 people per 100,000 population in England each year [2]. One in four men and one in five women aged 45 and over will have a stroke during their lifetime [3] with a quarter of new strokes being in those aged under 65 [1]. Stroke therefore represents a sizeable challenge on multiple levels. At the societal level, stroke is estimated to cost in the region of $£ 2.8$ billion per annum in the UK $[2,4]$. On a personal level, the "costs" are arguably greater; while one third of people who have a stroke fully recover, a third die, with the remaining third having to contend with residual motor and sensory abnormalities, many of whom also have associated psychological side-effects $[5,6]$. More specifically, stroke can result in impairments such as the loss of muscle strength [7-13], and dexterity and proprioception [14,15]. Additionally, postural steadiness (the ability to maintain balance during dynamic and static activities) is often reduced [16, 17]. As balance is an integral part of everyday functioning, alterations in this modality can have a detrimental effect on many aspects of a person's life including their ability to walk $[18,19]$.

Currently rehabilitation post stroke is predominantly limited to the acute and sub-acute stages with limited access beyond 6 months [20,21]. However evidence suggests that functional recovery can continue beyond six months, with the recovery plateau post stroke being strongly debated in the literature [22-24]. Yet how ongoing rehabilitation can be achieved presents a challenge given that current access to community-based therapies, in particular physiotherapy, has been described by stroke survivors as being too brief and time limited to promote best recovery $[25,26]$. 
The need to develop strategies for accessing further rehabilitation beyond the current NHS pathways is evident. Delivery of health and well-being interventions by non-healthcare professionals is not without precedence and is a growing area of interest [27-29]. For example, people living with cardiovascular conditions in the community are commonly referred to exercise groups run by professional fitness instructors [30]. Similarly more provision for the continuing input for stroke survivors from outside the health system is being seen, and the evidence for community based exercise after stroke schemes is growing and highlighted in policy and clinical stroke guidelines for further development [20,31,32].

Action for Rehabilitation from Neurological Injury (ARNI) is a UK based charity founded in 2001 by a stroke survivor which aims to help bridge this gap by providing functional training for people with stroke. The service is delivered by ARNI accredited exercise instructors (non-medical) and is focused on the achievement of functionally-oriented tasks through improving strength, endurance, balance and coordination, and motivation as described in the ARNI manual and a two day training programme [33]. ARNI training is a multimodal approach of which functional strength training is one component. For example, participants in the group format may practice sit to stand to strengthen hip and knee extensors. Consequently, improvement in strength is expected as a benefit of ARNI training. ARNI is mostly delivered on a one to one basis as opposed to a group format, although in service delivery models (e.g. Bedfordshire and Hertfordshire), a group format has been adopted which is a decision mostly driven by financial and personnel constraints [34]. While there are numerous personal testimonies to the success of the approach for individual stroke survivors [35], to date there is no empirical evidence of outcomes and uncertainty remains as to the effects of this training programme.

The aim of this 16 month pragmatic study was to evaluate the effectiveness and acceptability of ARNI functional training programme for people with stroke using a group model for service delivery. Findings from a qualitative evaluation relating to the acceptability of taking part in the ARNI training programme are reported elsewhere (Norris et al.-in press). This paper specifically reports the effectiveness of training based on data from a range of biomechanical, physical and psychosocial measures. Reported results can be used for the calculation of sample size in future larger studies, and provide insight into the potential obstacles of service delivery.

\section{METHODS}

A pragmatic mixed methods approach was used. The intervention provided was a 12 week, $11 / 2$ hour weekly group based ARNI programme [33]. Training was delivered by two exercise instructors to a maximum of 8 participants to ensure safety and to maximise the opportunity for individuals to have some 1:1 time with an instructor (whilst the remaining people continued exercising as part of the group) to address personal goals. In total, four groups completed the training programme, which is described in detail elsewhere [33]. The programme took place in a newly built leisure centre facility in West London, UK.

In line with the International Classification of Functioning, Disability, and Health (ICF) levels, impairment was assessed by biomechanical tests of strength and postural steadiness and activity was measured through the use of the Berg Balance Scale (BBS) and $10 \mathrm{~m}$ walk. The validated Patient Reported Outcome Measure, SIPSO, was used as a measure of both social and physical impact acting as an indicator of participation [36].

\subsection{Participants}

All participants who volunteered to take part in the study were community dwelling stroke survivors who had finished formal physical rehabilitation. Participants in the study were screened and referred by a physiotherapist and all received GP clearance before taking part in the training. In total 30 stroke survivors participated in the intervention. Thirteen participants (4 F, $9 \mathrm{M}$, mean age 53 years; range 19 - 80 years; average time post stroke 20 months; range 4 - 154 months) volunteered to

Table 1. Anthropometric data of participants.

\begin{tabular}{cccccc}
\hline PARTICIPANT & Gender & $\begin{array}{c}\text { WEIGHT } \\
(\mathrm{N})\end{array}$ & $\begin{array}{c}\text { AGE } \\
(\mathrm{Yr})\end{array}$ & SIDE & $\begin{array}{c}\text { TIME SINCE } \\
\text { STROKE } \\
\text { (months) }\end{array}$ \\
\hline 1 & $\mathrm{M}$ & 684 & 46 & $\mathrm{R}$ & 12 \\
2 & $\mathrm{M}$ & 733 & 32 & $\mathrm{R}$ & 154 \\
3 & $\mathrm{~F}$ & 752 & 19 & $\mathrm{R}$ & 7 \\
4 & $\mathrm{M}$ & 732 & 63 & $\mathrm{~L}$ & 11 \\
5 & $\mathrm{~F}$ & 730 & 58 & $\mathrm{~L}$ & 7 \\
6 & $\mathrm{~F}$ & 585 & 52 & $\mathrm{R}$ & 8 \\
7 & $\mathrm{M}$ & 817 & 33 & $\mathrm{R}$ & 17 \\
8 & $\mathrm{M}$ & 1040 & 48 & $\mathrm{~L}$ & 13 \\
9 & $\mathrm{M}$ & 877 & 76 & $\mathrm{R}$ & 4 \\
10 & $\mathrm{~F}$ & 612 & 49 & $\mathrm{R}$ & 12 \\
11 & $\mathrm{M}$ & 890 & 80 & $\mathrm{R}$ & 6 \\
12 & $\mathrm{M}$ & 528 & 56 & $\mathrm{~L}$ & 5 \\
13 & $\mathrm{M}$ & 831 & 76 & $\mathrm{R}$ & 4 \\
\hline
\end{tabular}

Note. Side refers to the paretic side: $\mathrm{R}=$ right, $\mathrm{L}=$ left. 
complete various aspects of the impairment and activity testing, which had an inclusion criteria of independent standing balance for a minimum of 2 minutes and the cognitive ability to follow simple instructions required for the strength tests (Table 1).

The SIPSO which was open to all participants was completed by 23 participants who equally had a diverse profile in terms of age and time since stroke. Figure 1 presents a flow chart of assessments completed and num- ber of participants at each stage whose data contributed to the results and analyses including withdrawals and reasons for non-completion. Demographics of participants who took part in the ARNI training are presented in Table 2. Ethics approval for the conduction of the study was obtained from the Brunel University School of Sport and Education Research Ethics Committee, and all participants provided informed consent before taking part in the study.

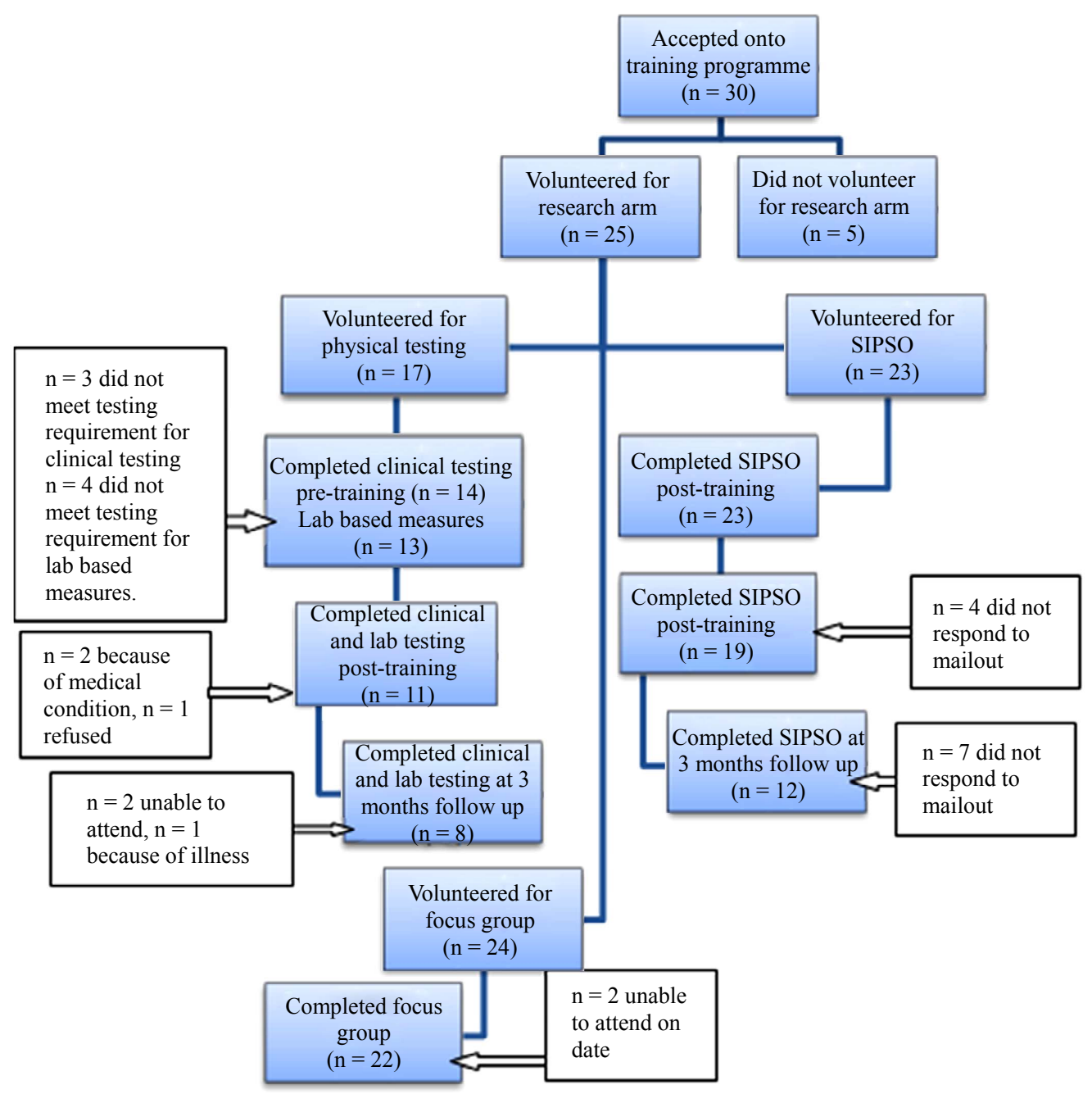

Figure 1. Flowchart of assessments completed and participation at each stage of the study.

Table 2. Demographic data of participants in the ARNI training.

\begin{tabular}{ccccc}
\hline Characteristic & Totals/Average (range) & Physical testing & SIPSO & Focus Groups \\
\hline Participants & 25 & 14 & 23 & 22 \\
Gender & $9 \mathrm{~F}, 16 \mathrm{M}$ & $4 \mathrm{~F}, 10 \mathrm{M}$ & $9 \mathrm{~F}, 13 \mathrm{M}$ & $8 \mathrm{~F}, 13 \mathrm{M}$ \\
Age (years) & $61.6(19-84)$ & $61.6(19-82)$ & $61.6(19-84)$ & $61.6(19-84)$ \\
Time since stroke (years) & $3.18(0.5-26)$ & $1.71(0.5-13)$ & $2.23(0.5-26)$ & $1.67(0.5-13)$ \\
\hline
\end{tabular}

Note. Physical testing refers to both clinical and lab based measures. 


\subsection{Procedure}

All measures were taken at baseline, post intervention and at 3 month follow-up and were repeated in the same order. They were conducted by the same researchers to maintain consistency.

For the tests of postural stability, the participant was asked to stand comfortably on a Kistler piezoelectric force platform (type 9281B11; Kistler, Switzerland); arms by their side, while maintaining their gaze on a (black circle) target mounted on a wall in front of them at three meters distance, and keep this position for $30 \mathrm{sec}-$ onds. No instruction with respect to the foot placement was provided. Coordinates of the centre of pressure (COP) in the anteroposterior (AP) and mediolateral (ML) directions recorded during the last 20 seconds of quiet standing were used to calculate eight measures of postural steadiness (total, AP, and ML excursions of the $\mathrm{COP}$; total, AP, and ML velocity of the COP; AP and ML range of COP excursion) according to Prieto et al. [37]. A maximum of three successful trials were collected based on the participant's ability to maintain their balance or follow the instructions for the duration of the trial and the average of the outcome measures were used in the analysis. The participant sat down between trials for thirty seconds to avoid fatigue.

It was decided to test the strength of the knee flexor and extensor muscle groups as an indicator of strength in the lower limb since a significant correlation amongst strength measured from different muscle groups of the lower limb after stroke has been reported [38,39]. A System 3 Biodex Isokinetic Dynamometry system (Biodex Medical Systems, New York, USA) was used for the assessment of strength of both the non-paretic (NP) and paretic (P) sides. The non-paretic limb was tested first. The participants were asked to produce maximum isometric knee extension or flexion torques while in a seated position (back rest angle at 85 degrees) at two different joint angles equal to $90 \%$ and $80 \%$ of the available range of motion between 90 degree of knee flexion and full extension. Using this procedure, torques were measured at angles closer to full knee extension. The order of angle at which strength was tested was alternated between the participants. Verbal encouragement was provided during the trials.

At each joint angle tested, the participant was asked to produce a maximum extension torque for five seconds followed by a maximum flexion torque for five seconds. There was a ten second rest interval between each extension-flexion torque pair. Three pairs of extension-flexion torques were produced at each joint angle. There was 120 seconds rest interval between the sets of extension-flexion torque production at the two angles. Maximum torques recorded during the last two pairs of torque production were normalised to the body weight $[40,41]$ and their average was used in the final analysis. Some participants were unable to produce torques above the value used by the system for gravity correction. For these individuals/sessions the gravity correction value determined by the system at the time of testing was used as the maximum torque to prevent missing values for the analysis. Accordingly, maximum torque could have been overestimated in such circumstances. Dynamometry and force platform data were sampled at $100 \mathrm{~Hz}$.

The Berg Balance [42] was carried out in accordance with published guidelines. The $10 \mathrm{~m}$ walk was repeated three times with a one metre lead in and out distance. The average of the three trials was calculated and the participant was given the option to rest between trials to minimise the impact of fatigue. The SIPSO was completed independently by the participants.

\subsection{Data Analysis}

Clinical data were analysed in SPSS (SPSS Inc.; ver. 18.02) using a variety of tests as appropriate including t-test, ANOVA, related samples Friedman's Two-way analysis of variance or a one tail sign test. For the biomechanical data, conventional paired t-test, one-way ANOVA, and MANOVA with repeated measures (side, joint angle, and testing session) was used to test the effect of training on balance and strength data between the $\mathrm{NP}$ and $\mathrm{P}$ sides at baseline and post-training, or across the three (baseline and post-training and follow up) testing sessions at the two joint angles. The level of significance for all tests was selected at $0.05(\alpha=0.05)$. An intention to treat analysis was conducted. Attendance rate was good averaging $74 \%-90 \%$ across the four groups.

\section{RESULTS}

Different number of participants took part in different tests. Figure 1 illustrates a flow chart of the study where reasons for drop outs are also included.

\subsection{Measures of Impairment}

Overall, postural stability performance of the participants did not show any statistically significant differences across the three sessions, or between the baseline and post-training sessions (all $p$ values $>0.05$ ). Results for the postural steadiness are illustrated in Figures $\mathbf{2}$ and $\mathbf{3}$.

For the extension torque at the baseline and posttraining sessions, the effects of side and joint angle were significant. As expected, the non-paretic (NP) legs were significantly stronger than the paretic $(\mathrm{P})$ legs $\left(\mathrm{F}_{[1,10]}=\right.$ $19.98 ; p=0.001)$, and the torques produced at the relatively more extended joint angle were smaller $\left(\mathrm{F}_{[1,10]}=\right.$ $44.61 ; p=0.0001)$. For the flexion torque, only the effect of side was significant where NP legs produced higher flexion torque values compared to the $\mathrm{P}$ legs $\left(\mathrm{F}_{[1,10]}=\right.$ 


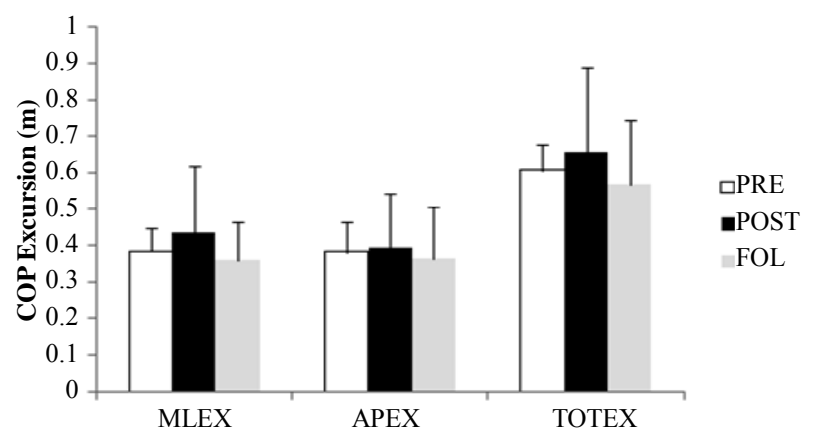

Figure 2. MLEX = excursion of the centre of pressure (COP) in the mediolateral (side-to-side) direction; APEX = excursion of the COP in the anteroposterior (forward-backward) direction; TOTEX $=$ total excursion of the COP. Error bars are group standard deviations. PRE, POST, and FOL refer to the pre-, post- and follow-up testing sessions.

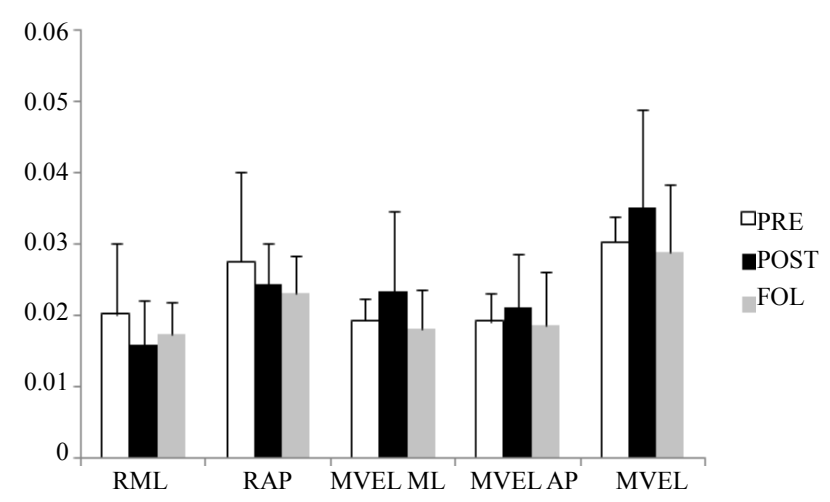

Figure 3. $\mathrm{R} \mathrm{ML}=$ range of $\mathrm{COP}$ excursion in the mediolateral direction $(\mathrm{m})$; R AP = range of COP excursion in the anteroposterior direction $(\mathrm{m})$; $\mathrm{M}$ VEL $\mathrm{ML}=$ mean velocity of the $\mathrm{COP}$ in the ML direction $(\mathrm{m} / \mathrm{s})$; M VEL AP = mean velocity of the COP in the AP direction $(\mathrm{m} / \mathrm{s}) ; \mathrm{M} \mathrm{VEL}=$ mean velocity of the COP $(\mathrm{m} / \mathrm{s})$; Error bars are group standard deviations. PRE, POST, and FOL refer to the pre-, post- and follow-up testing sessions.

9.26; $p=0.012$ ). Similar results were found when the extension torques results were analysed across three sessions $\left(\mathrm{F}_{[1,7]}=24.15 ; p=0.002\right.$ for the effect of side, and $\left(\mathrm{F}_{[1,7]}=54.60 ; p=0.0001\right.$ for the effect of joint angle $)$, but the difference between the NP and $\mathrm{P}$ sides for the flexion torques became non-significant (Figures 4 and 5).

\subsection{Measures of Activity}

Results for the measures of activity are shown in Table 3. Balance as measured by the BBS indicated a significant improvement across the testing sessions $\left(\mathrm{F}_{[2,11]}=\right.$ 10.63; $p<0.002$ ) and all participants improved their scores. The average change from baseline to follow-up sessions was 6 points. This exceeded the minimal detectable change (MDC) for chronic stroke (defined as $>6$ months post stroke) which was reported as 2.5 points on the BBS [43]. It should be further noted that there was a

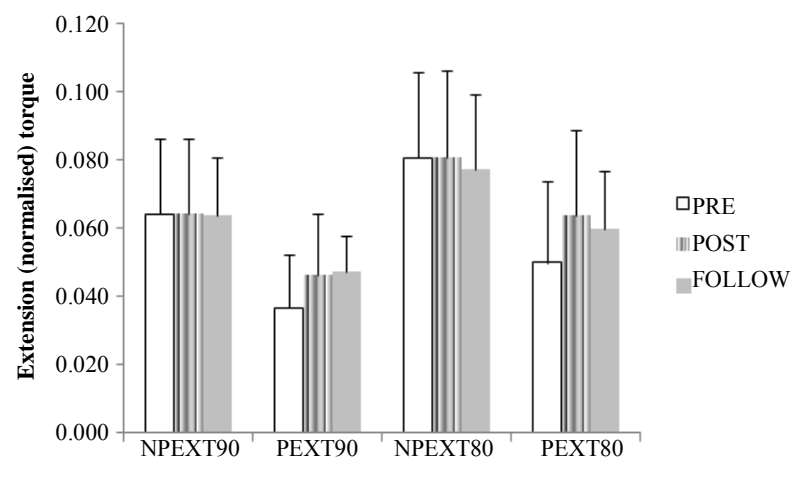

Figure 4. $\mathrm{NP}=$ non-paretic; $\mathrm{P}=$ paretic; $\mathrm{Ext}=$ extension torque; 90 and 80 refer to the testing joint position as percentage of available knee joint range of motion. 90 is a relatively more extended (straight) joint angle. Torque values are normalised to the body weight. Error bars are group standard deviations.

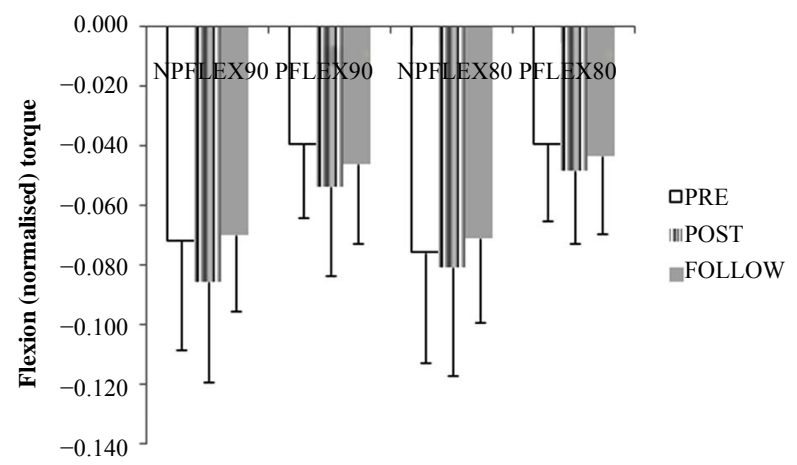

Figure 5. $\mathrm{NP}=$ non-paretic; $\mathrm{P}=$ paretic $; \mathrm{FLEX}=$ flexion torque; 90 and 80 refer to the testing joint position as percentage of available knee joint range of motion. 90 is a relatively more extended (straight) joint angle. Torque values are normalised to the body weight. Error bars are group standard deviations.

ceiling effect, for this measure for 2 participants at follow-up. As a consequence it was possible that the results did not fully demonstrate the improvement achieved.

The $10 \mathrm{~m}$ walk test also indicated an improvement. Nine of the eleven tested improved their walking speed post intervention and there was a general trend for improvement from baseline to the follow-up testing sessions. However, these changes did not reach significance level. The improvement from baseline to post-training session was significant $(p=0.03)$ on a 1-tail sign test. These pairwise results supported an overall trend towards improvement. MDC for chronic stroke is documented as a $16 \%$ change [44] and the baseline to follow up changes achieved this illustrating a $37 \%$ improvement in walking speed. The minimally clinically important difference (MCID) is reported in the subacute population as 0.16 $\mathrm{m} / \mathrm{s}$ [45]. This study indicated a MCID change of 0.15 $\mathrm{m} / \mathrm{s}$ in this chronic population.

\subsection{Measure of Participation}

The SIPSO scores indicated a borderline significant 
Table 3. Mean (SD) of outcome measures at baseline (T0), post intervention (T1), and 3 months follow-up (T2).

\begin{tabular}{ccccc}
\hline & T0 & T1 & T2 & Sig. \\
\hline BBS $^{2}$ & $44.09(11.90)$ & $49.36(11.13)$ & $50.25(8.78)$ & $\mathrm{F}_{(2,11)}=10.63 ; p<0.0022$ \\
10 m walk & $25.08(24.15)$ & $18.85(16.67)$ & $18.06(13.55)$ & $\mathrm{F}_{(2,11)}=1.69 \mathrm{~ns}$ \\
SIPSO total $^{1}$ & $23.32(6.45)$ & $26.84(6.81)$ & $28.83(6.10)$ & $\chi_{(2)}^{2}=6.26 ; p=0.0441$ \\
SIPSO section a (physical) $^{2}$ & $11.84(4.72)$ & $13.84(4.23)$ & $14.17(4.86)$ & $\mathrm{F}_{(2,22)}=1.72 \mathrm{~ns}$ \\
SIPSO section b (social) $^{2}$ & $11.47(3.41)$ & $13(3.96)$ & $13.75(3.02)$ & $\mathrm{F}_{(2,22)}=1.78 \mathrm{~ns}$ \\
\hline
\end{tabular}

Note. BBS - increase score indicate improvement, $10 \mathrm{~m}$ walk-decrease score indicates improvement, SIPSO-increase score indicates improvement. ${ }^{1}$ Analysed with Friedman's two way analysis of variance. ${ }^{2}$ Analysed with ANOVA.

improvement overall ( $p=0.044)$. However, when considered independently, the changes in physical and social subsections were non-significant (Physical: $\mathrm{F}_{[2,22]}=1.72$, ns; Social: $\mathrm{F}_{[2,22]}=1.78$, ns).

\section{DISCUSSION}

The purpose of the study was to evaluate the effectiveness of a twelve-week ARNI functional training programme delivered in a group format on measures of impairment, activity, and participation in stroke survivors. While no significant improvement in the strength of the lower limb and COP-based measures of postural steadiness were noted, an improvement in functional balance activity and a trend toward walking faster post intervention were seen. The SIPSO showed a significant overall improvement in the level of participation, but the physical and social subsections did not alter significantly.

\subsection{Effect of ARNI Functional Training on Strength}

\subsubsection{Knee Extensor Muscles Group}

In contrast to the results of the present study, improvement in muscle strength with functional training in stroke patients has been reported before [46-48]. However, in these studies examination of the isometric muscle strength was mostly conducted at angles which favoured torque production, i.e. at longer lengths of the muscle. In the present study the extensor muscles group were tested at short lengths at angles similar to those adopted during the stance phase of gait $[49,50]$. Inasmuch as extension torque was not tested at long muscle lengths, it was not possible to rule out if improvement in muscle strength had occurred at long lengths. Selective weakness of the hemiparetic muscles at shorter muscles lengths have been reported elsewhere in the literature, with this impairment attributed to the reduced rate of motor unit firing, differentially reduced excitability of the motor cortex, and changes in the operating range of the extensor muscles amongst others [51-54]. Present findings support the relative weakness of the knee extensor muscles group in the P compared to the NP side, and suggest that the employed functional training regime did not affect the underlying impaired mechanisms for the selective muscle weakness at shorter lengths in twelve weeks.

Lack of improvement in muscle strength with training in the present study could also be an artefact due to the methodology employed for the analysis of the dynamometry results. As stated before, some participants were not capable of producing torque above the values used by the dynamometry system for gravity correction at the initial assessment, but they produced recordable torque in the subsequent sessions (Figure 6). For these participants, we perhaps overestimated the maximal torque by using the individualised gravity correction value in the pre-testing session for the analysis. Therefore increase in muscle strength after intervention, represented by small recordable torque, might have not reached to the level of significance.

\subsubsection{Knee Flexor Muscles Group}

For the flexor group, the present results are partially consistent with those of Koo et al. [54] who employed a range of different joint angles to evaluate the strength of the elbow flexor muscles in a group of hemiparetic and control participants. Koo et al. [54] found no difference in the flexion torque between the two groups, but reported that at the shorter lengths of the muscle, i.e. at the more flexed positions, flexor muscles in the hemiparetic group were relatively weaker. In the current study, strength in the Hamstrings group was only assessed at the longer lengths. Therefore, the results are not against the notion of joint position dependency of muscular weakness in stroke survivors as discussed by Koo et al. and others (indicated above), but do not fully support the similarity of the knee flexion strength between the P and NP since a significant difference between the P and NP flexion torque was observed when the results of the preand post-testing sessions were compared.

\subsubsection{Relationship between Impairment and Activity}

Existence of a correlation between strength and activ- 

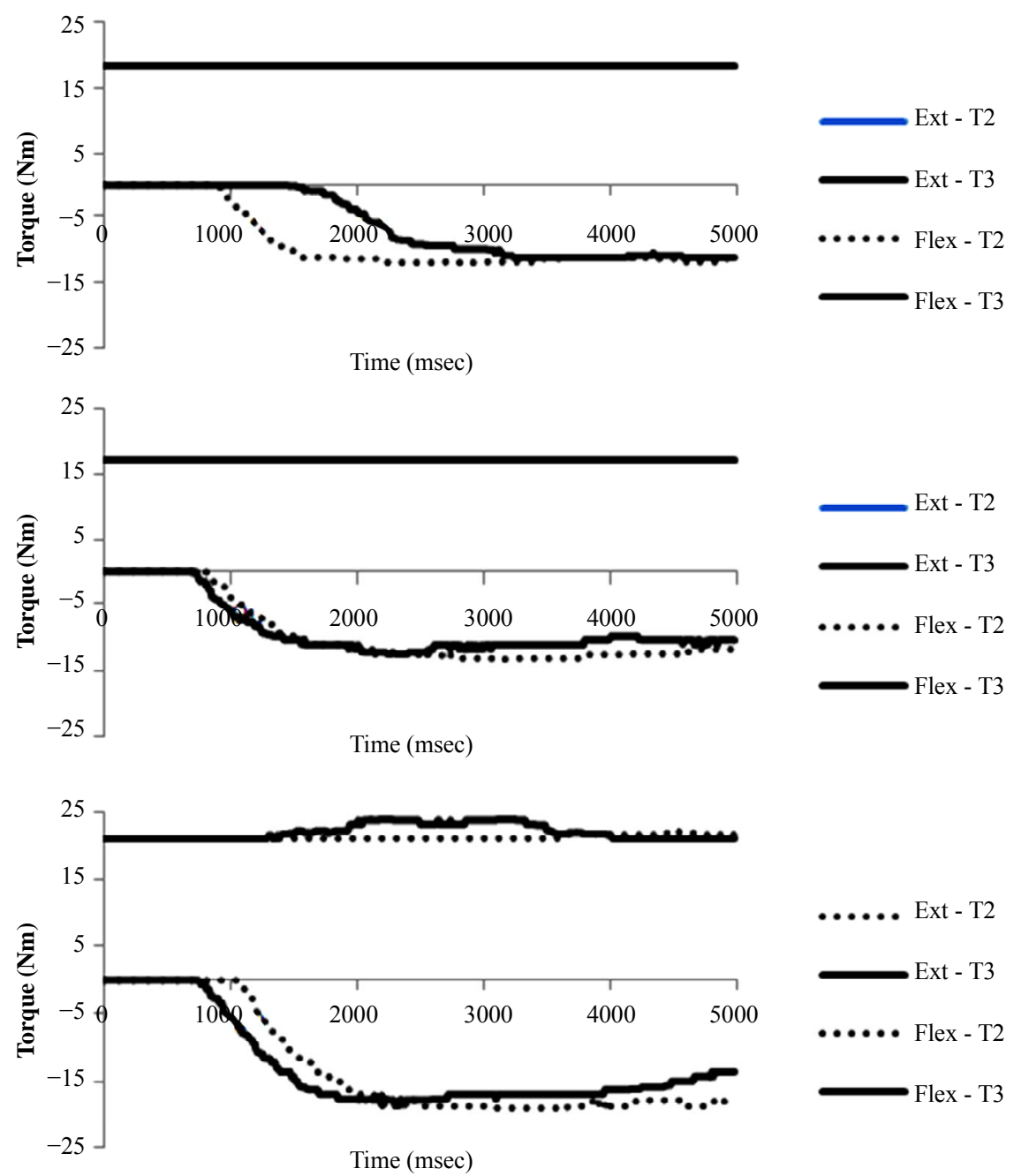

Figure 6. Extension and flexion torques produced by a participant at the $90 \%$ of the available range of motion in the pre- (upper panel) and post-training (middle panel), and follow-up (lower panel) sessions. Ext = extension torque; Flex = flexion torque; $\mathrm{T} 2$ and T3 refer to the second and third attempt from which maximum torques were calculated. Choice of sign for torques is arbitrary. The participant was incapable of producing extension torque at the tested angle in both pre- and post-training sessions (hence the overlapped flat lines), but produced recordable torques in the follow-up session during the third attempt.

ity (function) after stroke is a matter of controversy [11, $55,56]$. In the present study, a significant improvement in the BBS and a trend toward improvement in walking speed demonstrated partial improvement in the activity level which was not associated with improvement in strength. Klein et al. [12] also reported that the preferred gait speed was not limited by the weakness in stroke patients. There are some explanations for the apparent lack of association between measures of function and strength. It has been suggested that measures of strength similar to that employed in the present study are context specific and whether a measure of static strength (e.g. maximum isometric torque) can be representative of strength during dynamic tasks (such as walking) is not clear [57]. Other measures of strength (e.g. isokinetic peak torque and work of the knee extensor muscles) were significantly correlated to the gait velocity (particularly at faster speeds) in chronic stroke survivors [72,73]. Differences in the methodology (with isokinetic assessment of strength resembling more to the strength requirement during dynamic tasks), and recruitment of a group of more homogenous and less impaired participants in these studies might explain differences in the findings.

Studies which reported a significant correlation between the maximum isometric strength of the knee extensor and flexor muscles and walking speed and endurance in stroke population only reported low to medium values for the relationship between the two variables 
[58-60]. It has also been argued that motor behaviour of patient populations follows a non-linear trend where for some individuals, small (insignificant) alteration in one measure (e.g. strength) might result in a significant change in the behaviour (e.g. ability to stand or walk faster), whilst for others, it only prevents deterioration of the current condition [61]. This is similar to the suggestion made by Bohannon [62] who argued that a strength threshold related to the functional demand of a task should be reached for the successful completion of the task, beyond which increase in strength would not have any significant further influence on the efficiency of the task performance. In such circumstances improvement of strength might improve the speed of the task completion or act as a reserve against deterioration of the performance.

\subsubsection{Relationship between Clinical and Biomechanical Measures of Balance}

The significant improvement in balance as demonstrated by the BBS was in line with improvement reported in similar studies of exercise groups after stroke $[63,64]$. Of particular interest, however, was the improvement across all participants irrespective of their age and time post stroke. Such improvement was not associated with alteration in the COP-based measures of postural stability, or increased strength in the P leg [74]. Participants were included in the present study if they could maintain an unsupported stance for two minutes, and hence would score maximum points in the "standing unsupported" item of the BBS. Therefore, any changes in the other aspects of balance abilities assessed by the BBS could result in a lack of association between the results of the two tests. Only moderate correlation between the BBS and COP-based measures of balance has been reported before and authors attributed the findings to the different aspects of the balance abilities represented by these tests $[65,66]$. ARNI training included standing up from the floor and transfer of weight alternatively to the stronger and weaker sides of the body during functional tasks. It is therefore possible that the underlying mechanisms for the more dynamic balance activities benefited further from the training.

\subsection{ARNI Functional Training May Improve Quality of Life}

In view of these positive results in activity it is perhaps surprising that the SIPSO did not indicate more extensive changes in quality of life, although the trend was for some improvement. Previous work has questioned the direct link between physical capacity and quality of life [67] and the present results suggest that this relationship is certainly not linear. The SIPSO considers a variety of factors including both community ambulation and communication with friendship networks. Three participants had communication problems which naturally were not addressed in the ARNI training. Walking speed is a commonly used indicator of activity potential and therefore can have an important difference on the stroke survivors' ability to interact with their surroundings. However, while walking speed and balance are associated with community walking, other factors such as confidence and self-efficacy are equally important and were not measured in this study [68].

It is argued that results such as those reported in this paper reinforce the call to extend rehabilitation pathways beyond the initial acute and sub-acute periods and question the effectiveness of the current environment for stroke survivors to maximise their activity and functional potential [69]. They further highlight a need for an extended rehabilitation pathway supported by community resources. Previous research has involved fitness instructors in providing exercise to stroke survivors with some positive results [47,64]. However, research also indicates that uptake and continuation is limited by access to specialised gym facilities and self-consciousness created as a result of exercising with able bodied people [70,71]. This study was run in a health facility but required no specialist gym equipment, and while it was run in a group format, the results would indicate that sufficient training effect was achieved for at least the clinical measures to change.

\subsection{Limitations}

A sample of convenience was recruited for this evaluative study and there were no control participants. The participating group was comprised of a broad range of stroke survivors with different levels of motor impairment who received training in a group format which represented a real life situation. The standard model of the ARNI programme is on a $1: 1$ basis with resultant financial implications. The present study only supports the effectiveness of the ARNI training in a group format as a form of service delivery for stroke survivors, where specific trainings are individualised according to the abilities of the trainee [75].

Instructors who delivered the training were blinded to recruitment and hence the participants in the present study were not treated differently from the remaining of the training group. The research group was independent from ARNI.

\section{CONCLUSION}

In summary, twelve weeks of ARNI functional training positively affected activity and participation levels in a group of stroke survivors. Such improvements were however not associated with improvement at an impair- 
ment level. No adverse effect was observed as a result of participating in the training or assessment sessions, and hence, the training can be undertaken as an adjunct to rehabilitation plans or as part of a longer term personal plan for health and wellbeing.

\section{ACKNOWLEDGEMENTS}

Authors would like to thank London Borough of Hillingdon for financial support, Jackie O'Dowd for recruitment of the participants of this project.

\section{REFERENCES}

[1] National Audit Office (2010) Progress in improving stroke care: A good practice guide. National Audit Office.

[2] Townsend, N., Wickramasinghe, K., Bhatnagar, P., Smolina, K., Nichols, M., Leal, J., Luengo-Fernandez, R. and Rayner, M (2012). Coronary heart disease statistics. British Heart Foundation, London.

[3] Wolfe, C.D. (2000) The impact of stroke. British Medical Bulletin, 56, 275-286.

http://dx.doi.org/10.1258/0007142001903120

[4] Saka, O., McGuire, A. and Wolfe, C. (2009) Cost of stroke in the United Kingdom. Age Ageing, 38, 27-32. http://dx.doi.org/10.1093/ageing/afn281

[5] Hackett, M.L., Yapa, C., Parag, V. and Anderson, C.S. (2005) Frequency of depression after stroke: A systematic review of observational studies. Stroke, 36, 1330-1340. http://dx.doi.org/10.1161/01.STR.0000165928.19135.35

[6] Sandercock, P., Dennis, M., Warlow, C., Van Gijn, J., Hankey, G., Bamford, J. and Warlow, J. (2001) Stroke: A practical guide to management. Wiley, Hoboken.

[7] Ada, L., Dorsch, S. and Canning, C.G. (2006) Strengthening interventions increase strength and improve activity after stroke: A systematic review: 1. The Australian Journal of Physiotherapy, 52, 241-248.

http://dx.doi.org/10.1016/S0004-9514(06)70003-4

[8] Patten, C., Lexell, J. and Brown, H.E. (2004) Weakness and strength training in persons with poststroke hemiplegia: Rationale, method, and efficacy. Journal of Rehabilitation Research and Development, 41, 293-312. http://dx.doi.org/10.1682/JRRD.2004.03.0293

[9] Prado-Medeiros, C.L., Silva, M.P., Lessi, G.C., Alves, M.Z., Tannus, A., Lindquist, A.R. and Salvini, T.F. (2012) Muscle atrophy and functional deficits of knee extensors and flexors in people with chronic stroke. Physical Therapy, 92, 429-439. http://dx.doi.org/10.2522/ptj.20090127

[10] Hafer-Macko, C.E., Ryan, A.S., Ivey, F.M. and Macko, R.F. (2008) Skeletal muscle changes after hemiparetic stroke and potential beneficial effects of exercise intervention strategies. Journal of Rehabilitation Research and Development, 45, 261.

http://dx.doi.org/10.1682/JRRD.2007.02.0040

[11] Horstman, A.M., Beltman, M.J., Gerrits, K.H., Koppe, P., Janssen, T.W., Elich, P. and de Haan, A. (2008) Intrinsic muscle strength and voluntary activation of both lower limbs and functional performance after stroke. Clinical Physiology and Functional Imaging, 28, 251-261. http://dx.doi.org/10.1111/j.1475-097X.2008.00802.x

[12] Klein, C.S., Brooks, D., Richardson, D., McIlroy, W.E. and Bayley, M.T. (2010) Voluntary activation failure contributes more to plantar flexor weakness than antagonist coactivation and muscle atrophy in chronic stroke survivors. Journal of Applied Physiology, 109, 13371346. http://dx.doi.org/10.1152/japplphysiol.00804.2009

[13] Miller, M., Flansbjer, U. and Lexell, J. (2009) Voluntary activation of the knee extensors in chronic poststroke subjects. American Journal of Physical Medicine \& Rehabilitation, 88, 286-291.

http://dx.doi.org/10.1097/PHM.0b013e318198b569

[14] Bleyenheuft, Y. and Thonnard, J.L. (2011) Tactile spatial resolution in unilateral brain lesions and its correlation with digital dexterity. Journal of Rehabilitation Medicine, 43, 251-256. http://dx.doi.org/10.2340/16501977-0651

[15] Kiyama, R., Fukudome, K., Hiyoshi, T., Umemoto, A., Yoshimoto, Y. and Maeda, T. (2011) The loss of dexterity in the bilateral lower extremities in patients with stroke. Journal of Applied Biomechanics, 27, 122-129.

[16] Lubetzky-Vilnai, A. and Kartin, D. (2010) The effect of balance training on balance performance in individuals poststroke: A systematic review. Journal of Neurological Physical Therapy, 34, 127-137. http://dx.doi.org/10.1097/NPT.0b013e3181ef764d

[17] Marigold, D.S. and Eng, J.J. (2006) Altered timing of postural reflexes contributes to falling in persons with chronic stroke. Experimental Brain Research, 171, 459468. http://dx.doi.org/10.1007/s00221-005-0293-6

[18] Esquenazi, A., Ofluoglu, D., Hirai, B. and Kim, S. (2009) The effect of an ankle-foot orthosis on temporal spatial parameters and asymmetry of gait in hemiparetic patients. $P M \& R, 1,1014-1018$.

http://dx.doi.org/10.1016/j.pmrj.2009.09.012

[19] Patterson, K.K., Parafianowicz, I., Danells, C.J., Closson, V., Verrier, M.C., Staines, W.R., Black, S.E. and McIlroy, W.E. (2008) Gait asymmetry in community-ambulating stroke survivors. Archives of Physical Medicine and Rehabilitation, 89, 304-310. http://dx.doi.org/10.1016/j.apmr.2007.08.142

[20] Department of Health (2007) National stroke strategy. Department of Health, London.

[21] The Stroke Association (2010) Moving on: A vision for community based physiotherapy after stroke in England.

[22] Verheyden, G. and Ashburn, A. (2011) Stroke. In: Stokes, M. and Stack, E., Eds., Physical Management for Neurological Conditions, 3rd Edition, Elsevier Churchill Livingstone, London, 9-28.

[23] Hendricks, H.T., van Limbeek, J., Geurts, A.C. and Zwarts, M.J. (2002) Motor recovery after stroke: A systematic review of the literature. Archives of Physical Medicine and Rehabilitation, 83, 1629-1637. http://dx.doi.org/10.1053/apmr.2002.35473

[24] Demain, S., Wiles, R., Roberts, L. and McPherson, K. (2006) Recovery plateau following stroke: Fact or fiction? Disability and Rehabilitation, 28, 815-821. 
http://dx.doi.org/10.1080/09638280500534796

[25] The Stroke Association (2012) Struggling to recover. The Stroke Association, London.

[26] Winchcombe, M. (2012) A life more ordinary-Findings from the long-term neurological conditions research initiative.

[27] Horgan, J., Bethell, H., Carson, P., Davidson, C., Julian, D., Mayou, R.A. and Nagle, R. (1992) Working party report on cardiac rehabilitation. British Heart Journal, 67, 412-418. http://dx.doi.org/10.1136/hrt.67.5.412

[28] Morgan, O. (2005) Approaches to increase physical activity: Reviewing the evidence for exercise-referral schemes. Public Health, 119, 361-370. http://dx.doi.org/10.1016/j.puhe.2004.06.008

[29] Sharma, H., Bulley, C. and van Wijck, F.M.J. (2011) Experiences of an exercise referral scheme from the perspective of people with chronic stroke: A qualitative study. Physiotherapy, 98, 336-343.

http://dx.doi.org/10.1016/j.physio.2011.05.004

[30] Bethell, H., Lewin, R. and Dalal, H. (2009) Cardiac rehabilition in the United Kingdom. Heart, 95, 271-275. http://dx.doi.org/10.1136/hrt.2007.134338

[31] Brazzelli, M., Saunders, D.H., Greig, C.A. and Mead, G.E. (2012) Physical fitness training for patients with stroke: Updated review. Stroke, 43, e39-e40. http://dx.doi.org/10.1161/STROKEAHA.111.647008

[32] Intercollegiate Stroke Working Party (2012) Maintaining standards - The national clinical guideline for stroke. 4th Edition, London.

[33] Balchin, T. (2011) The successful stroke survivor. Bagwyn, Surrey.

[34] Luton stroke service on the world stage (2012). http://www.luton.gov.uk/news/Pages/Luton-stroke-servic e-on-the-world-stage.aspx

[35] Stroke survivors information page. http://www.arni.uk.com/members-page.html\#testimonials

[36] Trigg, R. and Wood, V.A. (2000) The subjective index of physical and social outcome [SIPSO]: A new measure for use with stroke patients. Clinical Rehabilitation, 14, 288299. http://dx.doi.org/10.1191/026921500678119607

[37] Prieto, T.E., Myklebust, J.B., Hoffmann, R.G., Lovett, E.G. and Myklebust, B.M. (1996) Measures of postural steadiness: Differences between healthy young and elderly adults. IEEE Transactions on Biomedical Engineering, 43, 956-966. http://dx.doi.org/10.1109/10.532130

[38] Bohannon, R.W. and Andrews, A.W. (1998) Relationships between impairments in strength of limb muscle actions following stroke. Perceptual Motor Skills, 87, 13271330. http://dx.doi.org/10.2466/pms.1998.87.3f.1327

[39] Bohannon, R.W. (2008) Is it legitimate to characterize muscle strength using a limited number of measures? Journal of Strength and Conditioning Research, 22, 166173. http://dx.doi.org/10.1519/JSC.0b013e31815f993d

[40] Jaric, S. (2002) Muscle strength testing: Use of normalisation for body size. Sports Medicine, 32, 615-631. http://dx.doi.org/10.2165/00007256-200232100-00002

[41] Jaric, S., Radosavljevic-Jaric, S. and Johansson, H. (2002)
Muscle force and muscle torque in humans require different methods when adjusting for differences in body size. European Journal of Applied Physiology, 87, 304307. http://dx.doi.org/10.1007/s00421-002-0638-9

[42] Berg, K.O., Wood-Dauphinee, S.L., Williams, J.T. and Gayton, D. (1989) Measuring balance in the elderly: Preliminary development of an instrument. Physiotherapy Canada, 41, 304-311. http://dx.doi.org/10.3138/ptc.41.6.304

[43] Liston, R.A. and Brouwer, B.J. (1996) Reliability and validity of measures obtained from stroke patients using the balance master. Archives of Physical Medicine and Rehabilitation, 77, 425-430. http://dx.doi.org/10.1016/S0003-9993(96)90028-3

[44] Flansbjer, U., Holmbäck, A.M., Downham, D., Lexell, J. and Sektion, I.V. (2005) What change in isokinetic knee muscle strength can be detected in men and women with hemiparesis after stroke? Clinical Rehabilitation, 19, 514522. http://dx.doi.org/10.1191/0269215505cr854oa

[45] Tilson, J., Sullivan, K., Cen, S., et al. (2010) Meaningful gait speed improvement during the first 60 days post stroke: Minimal clinically important difference. Physical Therapy, 90, 196-208. http://dx.doi.org/10.2522/ptj.20090079

[46] Bale, M. and Strand, L.I. (2008) Does functional strength training of the leg in subacute stroke improve physical performance? A pilot randomized controlled trial. Clinical Rehabilitation, 22, 911-921. http://dx.doi.org/10.1177/0269215508090092

[47] Cramp, M.C., Greenwood, R.J., Gill, M., Lehmann, A., Rothwell, J.C. and Scott, O.M. (2010) Effectiveness of a community-based low intensity exercise programme for ambulatory stroke survivors. Disability and Rehabilitation, 32, 239-247.

http://dx.doi.org/10.3109/09638280903095916

[48] Yang, Y.R., Wang, R.Y., Lin, K.H., Chu, M.Y. and Chan, R.C. (2006) Task-oriented progressive resistance strength training improves muscle strength and functional performance in individuals with stroke. Clinical Rehabilitation, 20, 860-870.

[49] Chen, C., Chen, H., Tang, S.F., Wu, C., Cheng, P. and Hong, W. (2003) Gait performance with compensatory adaptations in stroke patients with different degrees of motor recovery. American Journal of Physical Medicine \& Rehabilitation, 82, 925-935.

http://dx.doi.org/10.1097/01.PHM.0000098040.13355.B5

[50] Milovanović, I. and Popović, D.B. (2012) Principal component analysis of gait kinematics data in acute and chronic stroke patients. Computational and Mathematical Methods in Medicine, 2012, Article ID: 649743. http://dx.doi.org/10.1155/2012/649743

[51] Ada, L., Canning, C. and Dwyer, T. (2000) Effect of muscle length on strength and dexterity after stroke. Clinical Rehabilitation, 14, 55-61. http://dx.doi.org/10.1191/026921500671430626

[52] Ada, L., Canning, C.G. and Low, S.L. (2003) Stroke patients have selective muscle weakness in shortened range. Brain, 126, 724-731. http://dx.doi.org/10.1093/brain/awg066 
[53] Horstman, A., Gerrits, K., Beltman, M., Janssen, T., Konijnenbelt, M. and de Haan, A. (2009) Muscle function of knee extensors and flexors after stroke is selectively impaired at shorter muscle lengths. Journal of Rehabilitation Medicine, 41, 317-321. http://dx.doi.org/10.2340/16501977-0331

[54] Koo, T.K., Mak, A.F., Hung, L.K. and Dewald, J.P. (2003) Joint position dependence of weakness during maximum isometric voluntary contractions in subjects with hemi-paresis. Archives of Physical Medicine and Rehabilitation, 84, 1380-1386. http://dx.doi.org/10.2340/16501977-0331

[55] Gerrits, K.H., Beltman, M.J., Koppe, P.A., Konijnenbelt, H., Elich, P.D., de Haan, A. and Janssen, T.W. (2009) Isometric muscle function of knee extensors and the relation with functional performance in patients with stroke. Archives of Physical Medicine and Rehabilitation, 90, 480-487. http://dx.doi.org/10.1016/j.apmr.2008.09.562

[56] Ng, S. (2010) Balance ability, not muscle strength and exercise endurance, determines the performance of hemiparetic subjects on the timed-sit-to-stand test. American Journal of Physical Medicine \& Rehabilitation, 89, 497504. http://dx.doi.org/10.1097/PHM.0b013e3181d3e90a

[57] Fleishman, E.A. (1964) What do physical fitness test measure? A review of previous research. In: Cliffs, N.J., Ed., The structure and measurement of physical fitness, Prentice-Hall, Inc., Englewood, 27-37.

[58] Dorsch, S., Ada, L., Canning, C.G., Al-Zharani, M. and Dean, C. (2012) The strength of the ankle dorsiflexors has a significant contribution to walking speed in people who can walk independently after stroke: An observational study. Archives of Physical Medicine and Rehabilitation, 93, 1072-1076. http://dx.doi.org/10.1016/j.apmr.2012.01.005

[59] Pang, M. and Eng, J. (2008) Determinants of improvement in walking capacity among individuals with chronic stroke following a multi-dimensional exercise program. Journal of Rehabilitation Medicine, 40, 284-290. http://dx.doi.org/10.2340/16501977-0166

[60] Severinsen, K., Jakobsen, J.K., Overgaard, K. and Andersen, H. (2011) Normalized muscle strength, aerobic capacity, and walking performance in chronic stroke: A population-based study on the potential for endurance and resistance training. Archives of Physical Medicine and Rehabilitation, 92, 1663-1668.

http://dx.doi.org/10.1016/j.apmr.2011.04.022

[61] Buchner, D.M., Beresford, S.A., Larson, E.B., LaCroix, A.Z. and Wagner, E.H. (1992) Effects of physical activity on health status in older adults. II. Intervention studies. Annual Review of Public Health, 13, 469-488. http://dx.doi.org/10.1146/annurev.pu.13.050192.002345

[62] Bohannon, R.W. (2007) Muscle strength and muscle training after stroke. Journal of Rehabilitation Medicine, 39, 14-20. http://dx.doi.org/10.2340/16501977-0018

[63] Cramp, M.C., Greenwood, R.J., Gill, M., Lehmann, A., Rothwell, J.C. and Scott, O.M. (2010) Effectiveness of a community-based low intensity exercise programme for ambulatory stroke survivors. Disability and Rehabilitation, 32, 239-247.

http://dx.doi.org/10.3109/09638280903095916
[64] Stuart, M., Benvenuti, F., Macko, R., Taviani, A., Segenni, L., Mayer, F., Sorkin, J.D., Stanhope, S.J., Macellari, V. and Weinrich, M. (2009) Community-based adaptive physical activity program for chronic stroke: Feasibility, safety, and efficacy of the Empoli model. Neurorehabilitation Neural Repair, 23, 726-734. http://dx.doi.org/10.1177/1545968309332734

[65] Frykberg, G.E., Lindmark, B., Lanshammar, H. and Borg, J. (2007) Correlation between clinical assessment and force plate measurement of postural control after stroke. Journal of Rehabilitation Medicine, 39, 448-453. http://dx.doi.org/10.2340/16501977-0071

[66] Niam, S., Cheung, W., Sullivan, P.E., Kent, S. and Gu, X. (1999) Balance and physical impairments after stroke. Archives of Physical Medicine and Rehabilitation, 80, 1227-1233.

http://dx.doi.org/10.1016/S0003-9993(99)90020-5

[67] Hill, T., Gjellesvik, T., Moen, P., Tørhaug, T., Fimland, M., Helgerud, J. and Hoff, J. (2012) Maximal strength training enhances strength and functional performance in chronic stroke survivors. American Journal of Physical Medicine \& Rehabilitation, 91, 393-400. http://dx.doi.org/10.1097/PHM.0b013e31824ad5b8

[68] Schmid, A.A., Van Puymbroeck, M., Altenburger, P.A., Dierks, T.A., Miller, K.K., Damush, T.M. and Williams L.S. (2012) Balance and balance self-efficacy are associated with activity and participation after stroke: A crosssectional study in people with chronic stroke. Archives of Physical Medicine and Rehabilitation, 93, 1101-1107. http://dx.doi.org/10.1016/j.apmr.2012.01.020

[69] Mead, G. and Bernhardt, J. (2011) Physical fitness training after stroke, time to implement what we know: More research is needed. International Journal of Stroke, 6, 506-508. http://dx.doi.org/10.1111/j.1747-4949.2011.00679.x

[70] Rimmer, J.H., Wang, E. and Smith, D. (2008) Barriers associated with exercise and community access for individuals with stroke. Journal of Rehabilitation Research and Development, 45, 315-322. http://dx.doi.org/10.1682/JRRD.2007.02.0042

[71] Scianni, A., Teixeira-Salmela, L.F. and Ada, L. (2012) Challenges in recruitment, attendance and adherence of acute stroke survivors to a randomized trial in Brazil: A feasibility study. Revista Brasileira de Fisioterapia, 16, 40-45.

http://dx.doi.org/10.1590/S1413-35552012000100008

[72] Suzuki, K., Nakamura, R., Yamada, Y. and Handa, T. (1990) Determinants of maximum walking speed in hemiparetic stroke patients. The Tohoku Journal of Experimental Medicine, 162, 337-344. http://dx.doi.org/10.1620/tjem.162.337

[73] Hsu, A., Tang, P. and Jan, M. (2003) Analysis of impairments influencing gait velocity and asymmetry of hemiplegic patients after mild to moderate stroke. Archives of Physical Medicine and Rehabilitation, 84, 11851193. http://dx.doi.org/10.1016/S0003-9993(03)00030-3

[74] Genthon, N., Rougier, P., Gissot, A.S., Froger, J., Pelissier, J. and Perennou, D. (2008) Contribution of each lower limb to upright standing in stroke patients. Stroke, 39, 1793-1799. 
http://dx.doi.org/10.1161/STROKEAHA.107.497701

[75] Roland, M. and Torgerson, D.J. (1998) Understanding Controlled Trials: What are pragmatic trials? British Medical
Journal, 316, 285.

http://dx.doi.org/10.1136/bmj.316.7127.285 